actively been trying to move away from institutionalisation to community-based care, the inadequate number of fully qualified community mental health professionals, prejudice towards mental illnesses among the general population and less active participation of board-certified psychiatrists make this move difficult. H owever, a large investment in infrastructure, the development of programmes for community care, upgraded training and active research will lead to a more modern, communitybased, multidisciplinary approach to healthcare in So uth Korea.

\section{References}

Central Intelligence Agency (2004) World Factbook. Available at www.cia.gov/cia/publications/factbook/geos/ks.html. Last accessed 22 N ovember 2004.
Cho, M. J., Nam, J. J. \& Suh, G. H. (1998) Prevalence of symptoms of depression in a nationwide sample of Korean adults. Psychiatry Research, 81, 341-352.

Korea N ational Statistics O ffice (2003) Statistical Annual 2002. Daejeon: Korea $\mathrm{N}$ ational Statistics $\mathrm{O}$ ffice.

Suh, G. H. \& Shah, A. (2001) A review of the epidemiological transition in dementia - cross-national comparisons of the indices related to Alzheimer's disease and vascular dementia. Acta Psychiatrica Scandinavica, 104, 4-11.

Suh, G. H., Cho, D. Y., Rhoo, I. K., et al (1999a) Prevalence and risk factors of depressive symptomatology among the Korean elderly. Journal of the Korean Geriatrics Society, 2, 49-60.

Suh, G. H., Kim, J. K., Jung, Y. J., et al (1999b) Wish to die and associated factors in the rural elderly. Journal of Korean Geriatric Psychiatry, 3, 70-77.

Suh, G. H., Kim, J. K. \& Cho, M. J. (2003) Community study of dementia in the older Korean rural population. Australia and $\mathrm{New} Z$ Zealand Journal of Psychiatry, 37, 606-612.

Sunw00, D. (2001) Survey of the Long-Term Care Service Need of Old Persons and Policy Direction. Seoul: Korean Institute for $H$ ealth and Social Affairs.
Only recently has

Romania tried to add community

mental healthcare services to the traditional system of active

psychiatric

hospital care. This started by radically reducing the number of beds, but unfortunately without ensuring adequate community care programmes and services.

\title{
Psychiatry and geriatric psychiatry in Romania
}

\author{
Nicoleta Tataru
}

Senior Consultant Psychiatrist, Oradea, Romania, email: nicoleta tataru@hotmail.com; President of the Romanian Association of Geriatric Psychiatry, Member of the Honorary Board of the Romanian Association of Psychiatry, and Member of the Board of the International Psychogeriatric Association and of the Association of European Psychiatrists

omania is now in a period of transition from communism to democracy. Geographically, Romania, like other Eastern European countries, is on the border between the Western world and the Middle East and Asia; until December 1989 it was behind the 'Iron Curtain'.

It covers $237500 \mathrm{~km}^{2}$, divided into 42 districts. In 2002 it had a population estimated to be 21795000 . The unemployment rate was $10.5 \%$. Fourteen per cent of the general population were over the age of 65 . The infant death rate was 17.3 per 1000 and life expectancy at birth was 67.6 years for males and 71.1 years for females. The gross domestic product per capita (GDP) expressed in purchasing power parity (PPP) is US\$6041, and total health expenditure is $2.60 \%$ of GDP. The proportion of the national budget spent on the health system is $4 \%$, and around $2 \%$ of the total health budget is for mental health. There are 189 physicians per 100000 population.

\section{Mental health services}

$\mathrm{N}$ ationally, there are 908 psychiatrists (4.16 per 100000 population), of whom 260 are child psychiatrists (1.19 per 100000 population). They all work in the public health sector, although some also work in private ambulatory clinics. There are also psychologists and social workers in the mental healthcare system.

Most psychiatric services are provided by hospitals and out-patient clinics attached to the Ministry of $\mathrm{H}$ ealth. There are 38 psychiatric hospitals and many psychiatric departments in the general hospitals (a total of 17079 beds) as well as day hospitals (1222 beds) to care for patients with both acute and chronic mental illnesses; in addition there are 166 beds for patients with drug dependency. There are also 65 mental health centres for adults and children with mental illness. There are no private psychiatric hospitals.

The special needs of people with mental illness have not always been recognised and respected by the generic health services. However, a mental health law was passed in Romania only in August 2002 (Monitorul oficial al Romaniei, XIV, 589). This was the first step towards reform of the mental health services and care system. In chapter 4 of the law, the forms of specific mental health services existing in Romania are listed, along with care standards for people with mental disorders. O nly recently has Romania tried to add community mental healthcare services to the traditional system of active psychiatric hospital care. This started by radically reducing the number of beds, but unfortunately without ensuring adequate community care programmes and services. Many long-stay psychiatric wards were transferred to the 
social services. In the district of Bihor alone, 178 psychiatric beds out of 900 were transferred from N ucet Psychiatric Hospital (accountable to the Ministry of $H$ ealth) to the social services (accountable to the Department of Labour and Social Protection).

Stigma remains an obstacle in ensuring access to care for patients who are mentally ill. Stigma leads to the development of negative attitudes (including those of professionals), poor quality of treatment services and inadequate funding at both national and local level.

Standards need to be raised in basic mental healthcare, and in relation to patients' basic needs and quality of life (accommodation, food, sheltered housing, sheltered workplaces and community involvement).

\section{In-patient services}

People with acute or chronic mental disorders are treated in:

o psychiatric hospitals (for those with acute mental disorders)

O day hospitals

o long-stay accommodation

o psychiatric wards in general hospitals (when psychiatric hospitals are not locally available)

o the consultation-liaison psychiatry department in Bucharest U niversity General H ospital

O psychiatric departments in geriatric hospitals

o sheltered homes (for patients with schizophrenia) founded by non-governmental organisations (N GO s). These kinds of services are available in most but not all districts.

\section{Out-patient units}

In Romania out-patient services are available in only a few districts because there is still a severe lack of resources. The following types of service are usually available:

o out-patient or community assessment units

O day care centres

o primary care

o community mental health centres (which serve as a link between patients and their families, general practitioners and hospitals for acutely or chronically mentally ill people) (Tataru, 1997)

o community and social support services (organised by NGO s and churches in almost all districts).

Day programmes contribute to reducing stigma and discrimination against people with mental disorders by reducing their isolation and increasing the patients' abilities to face daily life.

\section{Home care}

In 2003, a programme began of follow-up home care for all patients, including elderly people with mental disorders and dementia. The programme consists of medical treatment and domiciliary services, such as home-helps and meals-on-wheels, and other help to enable patients to remain at home. There is also some financial support from the Department of Labour and Social Protection to compensate the families or carers of people who are chronically ill and those with handicaps (including those with dementia) who are treated at home.

\section{Mental health programmes}

A national mental health programme has been developed in recent years for the treatment of schizophrenia and depression, to provide free medication for patients from the onset of their illness, and also medication for inpatients in forensic psychiatric units. The national programme for elderly people with a mental illness is lacking financial support at present.

\section{Education}

In 1989 Romania had six schools of medicine; now there are 10. Medical education in psychiatry begins with a half-year programme during the last year of undergraduate study, which comprises theoretical and practical courses, seminars and training in psychiatric hospitals or psychiatric departments in general hospitals. These studies include basic knowledge of child and adolescent psychiatry. The curriculum is based around the nosographic criteria of ICD-10 and the classical clinical presentation of mental disorders. The main goal is to give doctors the capacity to recognise, diagnose and care for people with mental health problems.

The educational programme for psychiatrists continues with 5 years of postgraduate medical education, comprising: courses, workshops, mental health examinations, psychiatric interviews, case presentations and training in psychiatric hospitals with a senior consultant psychiatrist or professor of psychiatry. The curriculum for psychiatrists respects the ICD-10 and DSM-IV criteria for the diagnosis of mental disorders. Psychiatry residents are obliged to use the most well known American and English psychiatric books. During these 5 years, the residents can attend a fee-paying training programme or courses and workshops on different forms of psychotherapy, usually run by psychotherapists from W estern European countries. The current demand for training in psychotherapies, especially from recent generations of residents, is a consequence of the prohibition of these approaches (on ideological grounds) up to 1990.

Programmes in continuing medical education comprise postgraduate courses lasting 2-3 months and training in university psychiatric hospitals, as well as participation in national and international psychiatric congresses and conferences. There are also more specialist postgraduate training courses for child psychiatrists, geriatric psychiatrists and psychologists.

\section{Professional associations and publications}

Mental health professionals are organised into many scientific associations and societies, most of them founded after 1989. The largest of these is the Romanian Asso ciation of Psychiatry, of which nearly all Romanian
Stigma remains an obstacle in

ensuring access to care for patients who are mentally ill. Stigma leads to the development of negative attitudes

(including those of professionals), poor quality of treatment services and inadequate funding at both national and local level.

In 2003, a programme began of follow-up home care for all patients, including elderly people with mental disorders and dementia. The programme consists of medical treatment and domiciliary services. 
psychiatrists are members. 0 thers include the Romanian Mental Health League, the Romanian Alzheimer Society, the Romanian Association of Geriatric Psychiatry, the Romanian Association of Free Psychiatrists, the Romanian Association of $\mathrm{N}$ europsychopharmacology, the Romanian Association of Psychotherapy and the Romanian Association of Toxicology-Dependence. These associations organise annual local and national scientific meetings and conferences and stimulate their members to participate in national and international congresses.

Some European congresses have been organised in Romania: in 2000 the Romanian Association of Geriatric Psychiatry organised the 28th European Congress of Geriatric Psychiatry in 0 radea; in 2001 the Romanian Alzheimer Society organised the 10th European Conference on Alzheimer's Disease in Bucharest; and the 2002 meeting of the European College of $\mathrm{N}$ europsychopharmacology was held in Bucharest.

The Romanian Association of Psychiatry works in partnership with other European and international psychiatry associations to improve mental healthcare in Romania and is an active member of the World Psychiatric Association (there are 250 paying members). 0 ne of its initiatives has been to translate into Romanian many important documents, psychiatric books and diagnostic guidelines (e.g. ICD-10 and DSM-IV). The Romanian Association of Psychiatry publishes the Romanian Journal of Psychiatry (four issues a year) and the Romanian League for Mental $\mathrm{H}$ ealth publishes the Romanian Journal of M ental Health (three issues a year) and together with the Mental $\mathrm{H}$ ealth League in Moldavia publishes Psychiatry Today (three issues a year). There is also the Romanian Journal of Child and Adolescent Psychiatry.

\section{Geriatric psychiatry}

O Id age psychiatry has become a basic discipline for all socio-medical providers as well as a specialty for some physicians and health workers (World Health 0 rganization, 1996). In Romania, old age psychiatry has been officially recognised as a sub-specialty of psychiatry since 2001. As in other Eastern European countries, geriatric psychiatry is still not well represented. Scientific organisations such as the Romanian Alzheimer Society (established 1996), the Romanian Association of Geriatric Psychiatry (1999), the Romanian Medical Society of Research of Cognitive Disorders and Alzheimer's D isease (2001) try to improve this situation by organising postgraduate courses for young psychiatrists and general practitioners so that better care of the elderly will be provided.

The number of professionals working in the field is still very low, and they are therefore unable to satisfy the need for care of elderly people with mental disorders. A postgraduate 1-year course is run in Bucharest for a diploma in psychogeriatrics for psychiatrists, geriatricians and medical residents (C amus et al, 2003). In addition, an annual summer course on geriatric psychiatry is organised in Romania for psychiatrists from all Eastern European countries. These courses are organised as an Eastern European Initiative by the International Psychogeriatric Association, together with the Romanian Asso ciation of G eriatric Psychiatry.

General practitioners and community nurses are also involved in the care of the elderly and so an educational programme has been initiated that includes courses for family doctors.

The Romanian Association of G eriatric Psychiatry and the Romanian Alzheimer Society also participate in the pilot studies on Alzheimer's disease and suicide organised by the World Health $\mathrm{O}$ rganization.

\section{Mental health services for the elderly}

Elderly people with acute and chronic mental disorders, as well as those with dementia, are taken care of both in psychiatric short- and long-stay hospitals and in social services. The latter are not well placed to care for these patients, as there are insufficient staff with professional qualifications in social work or in geriatric psychiatry. Unfortunately there is not a clear picture of all geriatric services, nor are there epidemiological studies in this field. Certainly, as yet there are few psychogeriatric services and even fewer specialist care services for dementia patients.

The extension of outreach services to nursing and residential homes in conjunction with day care centres, day hospitals and residential care could be a valuable alternative to the high degree of institutionalisation of Romanian elderly people, with or without mental disorders.

\section{Psychiatry and human rights}

The protection of human rights and the dignity of persons with mental disorders has a relatively short history in Romania, although in 1652 Matei Basarab, the voivode (governor) of Walachia, in his Letter to $\mathrm{M}$ y Son, wrote promoting the abolition of punishment for individuals with mental disorders and recommended their living in monasteries while they were ill.

Generally, Romania's legislation is in keeping with principles set out by the World Health O rganization, $U$ nited $\mathrm{N}$ ations and so on concerning the protection of people with a mental illness. The legislation calls for adequate treatment and respect for the human rights of people with mental disorders.

Standards and practice regarding involuntary commitment in a psychiatric department have been improved since the introduction of the new mental health law in 2002 (see above). Criminal Code 114 relates to forensic psychiatry. Also in 2002, Decree 313 was introduced, which pertained to the prevention of individuals with mental disorders becoming dangerous; this decree has recently been improved.

Involuntary commitment to a psychiatric department or involuntary treatment in an ambulatory setting of individuals with mental disorders is now established; which of the two orders is used depends on the mental state and the degree of danger. There are legal and ethical 
limits to involuntary commitment; for example, it may not be indefinite (as it was before the 1960s).

There is no legal discrimination against people with mental disorders but they are nevertheless discriminated against in other ways. Since 1990, because of financial problems, few patients have been able to find employment. The tolerance of society has decreased. Since 1990 it has been necessary to create committees to investigate abuse during involuntary commitment. $0 \mathrm{n}$ the other hand, before 1990 some individuals with (and even some without) mental disorders were committed to a psychiatric department to protect them.

\section{Conclusions}

o In Romania, there is a push to re-orientate mental services from being centred on hospitals towards a community care focus.

o People with chronic mental disorders, including dementia, are taken care of both in long-stay psychiatric hospitals and by social services, where the personnel are inadequately trained to care for them.

- Stigma remains an obstacle in ensuring access to care for patients with a mental illness. The battle against stigmatisation needs to be prioritised.

o There is considerable room for improvement in education and training in psychiatry, in research, and in the promotion of mental health and illness prevention.

o It is important for the future development of community services to distinguish between care and treatment.

o The basic quality of care for those who are mentally ill needs to be improved by: developing a community psychiatric network based on geographical catchment areas; developing a complex rehabilitation programme with more substantial social and financial support; involving the community, carers and users more; and involving the government and local authorities in mental healthcare.

In Romania, as in all former communist countries, there are economic problems and a need for national fundraising to support national psychiatric organisations and services.

\section{References}

Camus, V., Katona, C., De Mendonca Lima, C. A., et al (2003) Teaching and training in old age psychiatry: a general survey of the World Psychiatric Association member societies. International Journal of Geriatric Psychiatry, 18, 694-699.

Tataru, N . (1997) Project for the development of an ambulatory and semi-ambulatory centre for the third age. Dementia and Geriatric Cognitive Disorders, 8, 128-131.

World Health Organization, Division on Mental Health and Prevention of Substance Abuse (1996) Psychiatry of the Elderly - A Consensus Statement. Geneva: WHO.

\section{Mental health services in Uganda}

\section{Fred Kigozi}

Medical Director/Senior Consultant Psychiatrist, Butabika National Referral Teaching Hospital, email: buthosp@infocom.co.ug

ganda is a landlocked developing country in East Africa with an estimated population of 24.8 million people (2002 census). At independence (in 1962) U ganda was a very prosperous and stable country, with enviable medical services in the region. This, however, was destroyed by a tyrant military regime and the subsequent civil wars up to 1986, when the current government took over the reigns of power.

The 2000/2001 U ganda D emographic and $\mathrm{H}$ ealth Survey (UDHS) and the 2002 census report revealed several poor demographic and health indicators. The data showed a high population grow th rate (in excess of 3\% per annum) due to the high fertility rate, estimated at seven children per woman. The age structure is therefore young, with about half the population below 15 years of age. The infant mortality rate was 88 per 1000 live births and maternal mortality rate 50.4 per 10000 live births. Life expectancy was 43 years. Gross domestic product (GDP) per capita was around U $\$ 300$.

By the mid-1980s, the economy had been destroyed and many of the medical personnel had left the country. The net effect was the current low GDP and poor health indices, which, how ever, have gradually improved over the last decade or so. The continuing civil wars in the north and north-eastern parts of the country continue to drain valuable national resources, and the affected areas have very poor socio-demographic and health indices. The net effect has been a dilapidated infrastructure and psychosocial problems, mainly manifesting as posttraumatic stress disorders.

$U$ ganda is one of the countries in sub-Saharan Africa that was hard hit by the HIV/AIDS epidemic; however, with a sound government strategy and a timely response, HIV infection has been reduced from a prevalence of $20-28 \%$ in the mid-1980s to the current $5.6 \%$. U ganda
There is no legal discrimination

against persons with mental

disorders but they

are nevertheless

discriminated

against in other

ways. Since 1990,

because of

financial

problems, few

patients have been able to find employment. The tolerance of society has decreased.

Uganda ... was hard hit by the HIV/AIDS epidemic; however, HIV infection has been reduced from a prevalence of $20-28 \%$ in the mid-1980s to the current 5.6\%.

Uganda stands as one of the few developing countries that has succeeded in reversing the tide of the HIV epidemic. 